\title{
On the diurnal variability of particle properties related to light absorbing carbon in Mexico City
}

\author{
D. Baumgardner ${ }^{1}$, G. L. Kok ${ }^{2}$, and G. B. Raga ${ }^{1}$ \\ ${ }^{1}$ Centro de Ciencias de la Atmósfera, Universidad Nacional Autónoma de México, Mexico \\ ${ }^{2}$ Droplet Measurement Technologies, Boulder, Colorado, USA \\ Received: 8 January 2007 - Published in Atmos. Chem. Phys. Discuss.: 31 January 2007 \\ Revised: 5 April 2007 - Accepted: 18 April 2007 - Published: 14 May 2007
}

\begin{abstract}
The mass of light absorbing carbon (LAC) in individual, internally mixed aerosol particles was measured with the Single Particle Soot Photometer (SP2) in April of 2003 and 2005 and evaluated with respect to concentrations of carbon monoxide (CO), particle bound polycyclic aromatic hydrocarbons (PPAH) and condensation nuclei $(\mathrm{CN})$. The LAC and CO have matching diurnal trends that are linked to traffic patterns and boundary layer growth. The PPAH reaches a maximum at the same time as CO and LAC but returns rapidly back to nighttime values within three hours of the peak. The number of particles containing LAC ranges between $10 \%$ to $40 \%$ of all particles between $150 \mathrm{~nm}$ and $650 \mathrm{~nm}$ and the mass is between $5 \%$ and $25 \%$ of the total mass in this size range. The average LAC equivalent mass diameter varies between 160 and $230 \mathrm{~nm}$ and the thinnest coating of non-light absorbing material is observed during periods of maximum LAC mass. The coating varies between $10 \mathrm{~nm}$ and $30 \mathrm{~nm}$ during the day, but is a strong function of particle size. The mass absorption cross sections, $\sigma_{\mathrm{abs}}$, derived from the SP2, are $5.0 \pm 0.2 \mathrm{~m}^{2} \mathrm{~g}^{-1}$ and $4.8 \pm 0.2 \mathrm{~m}^{2} \mathrm{~g}^{-1}$, dependent on the optical model used to describe LAC mixtures. The LAC contributes up to $50 \%$ of the total light extinction in the size range from $100 \mathrm{~nm}$ to $400 \mathrm{~nm}$. The estimated emission rate of LAC is 1200 metric tons per year in Mexico City, based upon the SP2 measurements and correlations between $\mathrm{LAC}$ and $\mathrm{CO}$.
\end{abstract}

\section{Background}

The environmental impact of atmospheric aerosols is multifaceted as a result of the wide range in concentration and size, complexity of chemical composition and optical properties that contribute to their role in global climate change (Charl-

Correspondence to: D. Baumgardner

(darrel@servidor.unam.mx) son et al., 1992), photochemistry (Dickerson et al., 1997; Jacobson, 1998; Raga and Raga, 2000) and cloud processes (Hobbs, 1991). Light absorbing carbon (LAC) often referred to as black carbon or soot ${ }^{1}$ is an anthropogenic component of atmospheric particles whose environmental impact has been recognized for more than 100 years (Novakov, 1982). These ubiquitous particles found throughout the world's atmosphere and produced primarily by incomplete combustion of fossil fuel and biomass burning (Ghan and Penner, 1992), may have much longer lifetimes than other types of aerosol particles.

The climatic importance of LAC is a result of the high efficiency with which it scatters and absorbs light over a wide range of solar and infrared wavelengths. This is highlighted by comparing the efficiency with which radiant energy is removed by LAC and ammonium sulfate. This latter compound is commonly found mixed with LAC (Johnson et al., 2005). Figure 1 illustrates the difference in extinction efficiency between these two types of particles at $550 \mathrm{~nm}$, the wavelength of maximum solar radiance. The extinction was calculated incorporating Mie theory (Bohren and Huffman, 1983) and assuming spherical particles with the refractive indices of ammonium sulfate (1.43-0.0i) and LAC (1.950.79i) at this wavelength (Volz, 1972; Bond and Bergstrom, 2006).

For diameters smaller than $300 \mathrm{~nm}$, LAC has an extinction efficiency that is larger than sulfate by several orders of magnitude and is comparable at larger diameters. Although the number concentration of LAC in the free troposphere

\footnotetext{
${ }^{1}$ Bond and Bergstrom (2006) evaluate in detail the light absorption by carbonaceous particles and discuss the various terminologies that have been used to describe particles that contain carbon. Given that the measurements discussed in the current manuscript are made with an instrument that utilizes the property of light absorption by some forms of carbon, we will use the term suggested by Bond and Bergstrom, light absorbing carbon (LAC), throughout the remainder of this article.
} 


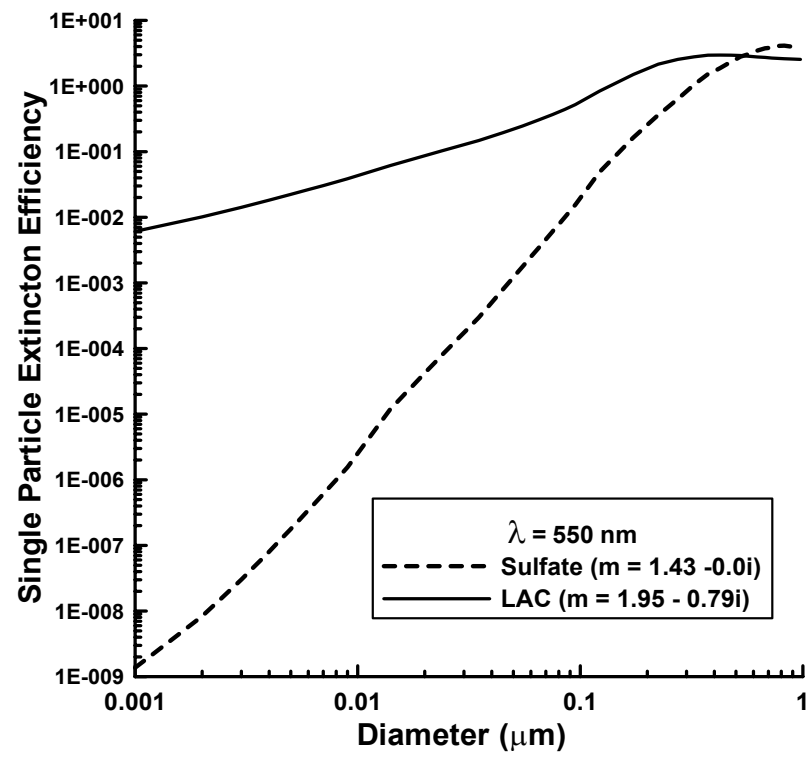

Fig. 1. The extinction efficiency of LAC (solid) is compared with that of ammonium sulfate (dashed).

is generally less than that of sulfate aerosols its impact on radiative fluxes can be similar. Furthermore, as shown by recent modeling and laboratory studies (Bond et al., 2006; Mikhailov et al., 2006) coatings of non-light absorbing material on the surface of LAC will enhance the absorption efficiency by factors of 1.5 to 2.5 .

The optical properties of LAC must be taken into account when interpreting measurements by remote sensors such as lidars, sun photometers and satellites. The algorithms that are applied for extracting information from these measurements incorporate assumptions about the shape of the size distribution, the composition and optical characteristics. In some cases the objective is to derive particle properties whereas in other applications aerosols are a source of interference to be removed. Many years of airborne and ground based measurements have contributed to the parameterization of aerosol properties to use in these algorithms; however, until recently, very few measurements had been made of the size differentiated LAC characteristics.

The study described herein is a particle by particle evaluation of LAC properties in Mexico City, the diurnal trends and the links to other related anthropogenic gases and aerosols. The remainder of the paper describes the instrumentation, evaluates the physical and optical characteristics of LAC and discusses the relationships between primary emissions and meteorological processes with respect to the aerosol properties.

\section{Measurement and analysis methodology}

The measurements were made with a Single Particle Soot Photometer ${ }^{2}$ (SP2), a nephelometer and Particle Soot Aerosol Photometer ${ }^{3}$ (PSAP), a Photoelectric Aerosol Sensor $^{4}$ (PAS-2000) and a condensation nucleus (CN) counter (TSI Model $3010^{5}$ ).

\subsection{LAC physical properties}

The SP2 employs a patented technique (Stephens et al., 2003) that combines the principles of light scattering, absorption and emission to derive the diameter, mass and incandescence temperature of individual aerosol particles in the diameter range (for the current study) from 150 to $600 \mathrm{~nm}$ (Baumgardner et al., 2004; Schwarz et al., 2006; Moteki and Kondo, 2006). Particles enter the sample cavity of the SP2 (the typical sample flow rate for the instrument is $2 \mathrm{~cm}^{3} \mathrm{~s}^{-1}$ ) and while passing through the beam of a diode-pumped Nd:YAG laser (1.064 $\mu \mathrm{m}$ wavelength) they scatter and absorb light. Two cones of scattered light, $30^{\circ}-60^{\circ}$ and $120^{\circ}-150^{\circ}$, are collected by the optics and focused on a photodetector that produces a voltage signal proportional to the scattering intensity. Particle diameter is derived from the scattered light using classical Mie theory.

Particles that contain material that absorbs light at the wavelength of the laser are heated and reach a temperature at which they incandesce and emit light at a wavelength that is a function of the temperature. Two detectors, each with filters for passing different wavelengths, measure the emitted light. The temperature is derived from the ratio of signals from these detectors (Baumgardner et al., 2004; Schwarz et al., 2006; Moteki and Kondo, 2006). The intensity of the emitted light is proportional to the mass of the light absorbing material and the temperature of incandescence identifies the composition.

Calibration of the SP2 is carried out with commercially available spherical particles. Monodispersed, polystyrene latex spheres are used to calibrate the scattering signals and glassy carbon spheres of known density were size-selected with an electrostatic classifier for calibration of the incandescence signals. Incandescing particles are sized in the range of 3-300 fg/particle (120 to $650 \mathrm{~nm}$ mass equivalent diameter at $1.42 \mathrm{~g} \mathrm{~cm}^{-3}$ density). The optical diameter is derived from the scattering signal and ranges from 100 to approximately $400 \mathrm{~nm}$, depending on the assumed refractive index. The scattering and incandescence signals are recorded particleby-particle such that the instrument is sensitive to very low concentrations of LAC.

The thickness of the non-light absorbing coating on each LAC containing particle is estimated by comparing the mass

\footnotetext{
${ }^{2}$ Droplet Measurement Technologies (DMT), Boulder, CO.

${ }^{3}$ Radiance Research, Seattle, WA

${ }^{4}$ Ecochem Analytic, West Hills, CA

5 Thermal Systems Incorporated, St. Paul, MN
} 
equivalent diameter, $D_{\text {mass_eqv }}$, of the LAC with the optical diameter, $D_{\text {optical }}$, of the coated particle. The mass equivalent diameter is derived from

$D_{\text {mass_eqv }}=(6 \mathrm{MLAC} / \pi \rho)^{1 / 3}$

And the layer thickness, $\mathrm{W}$, is

$W=\left(D_{\text {optical }}-D_{\text {mass_eqv }}\right) / 2$

where MLAC is the LAC mass, $\rho$ is the assumed density of the LAC in the particle, taken here to be $1.90 \mathrm{~g} \mathrm{~cm}^{-3}$ (Bond and Bergstrom, 1999), and $D_{\text {optical }}$ is the diameter of the coated particle estimated from the light scattering signal.

An advantage of the SP2's optical design is that the collection of scattered light over a wide solid angle decreases the sensitivity of the derived optical diameter to variations in the refractive index. As seen in Fig. 2, using the ammonium sulfate and LAC particles as an example, the scattering cross sections are similar even though the refractive indices are quite different. In the current study, the derivation of $D_{\text {optical }}$ from the scattering signal assumes ammonium sulfate when there is no incandescence and an average mixture of $50 \%$ LAC and 50\% ammonium sulfate by mass when there is incandescence. The components of the assumed mixture are based upon an analysis by Johnson et al. (2005) who found that a large majority of the LAC were mixed with ammonium sulfate. The $50 \%$ mixture is an estimate based upon the average mixing fraction, $D_{\text {mass_eqv }} / D_{\text {optical }}$, derived from the SP2. As will be discussed below, this fraction varied between 30 and $60 \%$. The average refractive index for this mixture is 1.72-.40i. The choice of this refractive index limits the uncertainty in derived diameter to a maximum of $\pm 30 \mathrm{~nm}$ as shown by the box drawn in Fig. 2. It is important to note that the measured MLAC is insensitive to the depth of the non-light absorbing coating (Slowik et al., 2006; Moteki and Kondo, 2006).

In addition to the uncertainty in $D_{\text {optical }}$ due to the assumption of refractive index, an additional error arises due to the heating of the particle by light absorption when it contains LAC. As pointed out by Gao et al. (2007), the diameter derived from the scattering peak measured by the SP2 will be an underestimate when the particle has a core of LAC. This is because the particle will begin heating as it enters the beam and the size will begin to decrease as the material evaporates. The rate at which it evaporates will depend on the amount of LAC and the volatility of the non-LAC material. There is a technique for obtaining a more accurate estimate of the particle size prior to the point at which it begins to evaporate (Gao et al., 2007) but it requires a hardware modification that the SP2 in the present study did not have. Hence, although it is likely that the $D_{\text {optical }}$ for particles containing LAC will be an underestimate, and the subsequent thickness of the layer that is derived from Eq. (2) will also be an underestimate, we can only estimate the magnitude of the error.

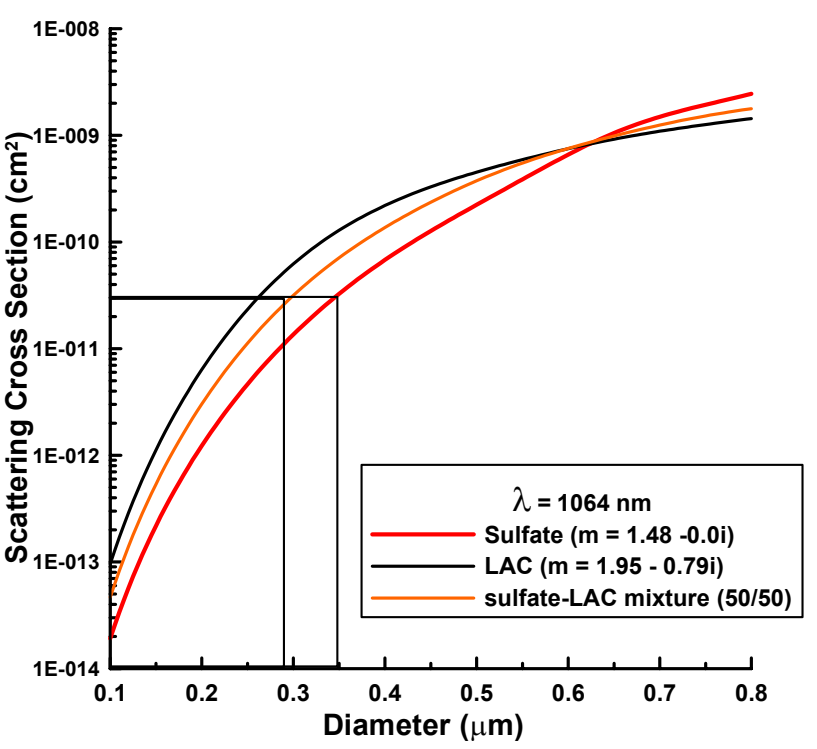

Fig. 2. Scattering cross sections for sulfate (red) and LAC (black) and a 50/50 mixture of sulfate and LAC (orange) particles as a function of particle size for the collection angles $\left(30^{\circ}-60^{\circ}\right.$ and $120^{\circ}-$ $150^{\circ}$ ) and wavelength of the SP2 laser.

A detailed description of the theory of operation, uncertainties in determining the size and mass of LAC and measurement limitations are documented elsewhere (Schwarz et al., 2006; Moteki and Kondo, 2006). For the interpretation of the measurements presented in the present study, the estimated uncertainties in LAC mass, $D_{\text {optical }}, D_{\text {mass_eqv }}$ and coating thickness are $\pm 20 \%, \pm 50 \%, \pm 30 \%$ and $\pm 58 \%$, respectively.

\subsection{LAC optical properties}

The scattering, absorption and extinction coefficients, $B_{\text {scat }}$, $B_{\text {abs }}$ and $B_{\text {ext }}$, at an incident wavelength of $\lambda=550 \mathrm{~nm}$, are derived for individual particles measured by the SP2 using optical efficiencies calculated from Mie theory (Bohren and Huffman, 1983) and assuming that the particles are spherical. Two approaches were taken to calculate the optical parameters based upon the fraction of LAC in a particle. The first approach that is designated "mixed", assumes a homogeneous mixture of LAC with the non-light absorbing material. A look-up table was generated that contains refractive indices for particles in the size range of the SP2 and with 21 mixtures of LAC with a refractive index of 1.95-0.79i and ammonium sulfate with refractive index of $1.48-0.00 \mathrm{i}$. The volumetric fraction of LAC in a particle is varied between 0 and 1 in 0.05 steps and the refractive index of the mixture is computed using the volume mixing rule (Bohren and Huffman, 1983). For example a particle containing $10 \%$ LAC by volume will have a refractive index of $(0.9 * 1.48+0.1 * 1.95)$ $0.1 * 0.79 \mathrm{i}$. The second approach, following the suggestion of 
Bond and Bergstrom (2006) assumes that all LAC in a particle is concentrated in a core that is encapsulated with a layer of ammonium sulfate. In this case, the look-up table has the same number of categories with LAC fraction varying between 0 and 1, but the optical properties are calculated using the optical shell model of Bohren and Huffman (1983). The results from this second approach are labeled "coated" in the later discussions.

The scattering, absorption and extinction coefficients and the single scattering albedo are computed by determining the fraction of LAC in each particle and finding the optical parameters associated with this fraction in the "mixed" and "coated" lookup table. The LAC fraction is computed from the cube of the ratio of $D_{\text {mass_eqv }}$ to $D_{\text {optical }}$. The absorption coefficient, normalized by the LAC mass, is calculated and referred to here as the mass absorption cross section (MAC), $\sigma_{\mathrm{abs}}$, following the terminology suggested by Bond and Bergstrom (2006).

An independent measurement of $B_{\text {abs }}$ was made with the PSAP, an instrument that uses the integrating plate technique (Bond et al., 1999). Particles are collected on a filter and the transmission of green light through this filter is measured in real time. By definition, the value of $B_{\text {abs }}$ is

$$
B_{\mathrm{abs}}=(A / V) \ln \left(I / I_{0}\right)
$$

where $I$ and $I_{0}$ are the transmitted and incident light intensities, $A$ is the area of the filter covered by aerosol particles and $V$ is the volume of air that passed through the filter to deposit a given layer of particles. The source of incident radiation in the PSAP is a light emitting diode $(\lambda=550 \mathrm{~nm})$ and particles are collected on a $10 \mathrm{~mm}$ diameter quartz filter. The light is transmitted through a second filter, unexposed to ambient air, and is the reference for the incident radiation, $I_{0}$. Detailed laboratory studies of these instruments (Bond et al., 1999) have arrived at an empirical correction to Eq. (3) that accounts for the scattering of the aerosol on the collection filter.

$B_{\text {abs }}=\left(B_{\text {abs_measured }}-0.40 B_{\text {scat_mreasured }}\right) / 2.2$

$B_{\text {abs_measured }}$ is the absorption coefficient derived from (3) and $B_{\text {scat_mreasured }}$ is the scattering coefficient measured with a nephelometer. This equation corrects for the effects of light scattering from particles on the filter, an interference that decreases the transmission through the filter, and for matrix effects of the quartz fibers that also enhance the measured attenuation and lead to overestimates of $B_{\text {abs }}$. Additional corrections are made for variations in the diameter of the aerosol deposit and changes in flow volume related to the differences in the altitude of Mexico City and Seattle, Wa, where the instrument flow meter was calibrated.

\subsection{Particle chemistry}

Particle-bound polycyclic aromatic hydrocarbon (PPAH) was measured with the PAS 2000 that uses $207 \mathrm{~nm}$ light from an Excimer lamp with energies of $6.7 \mathrm{eV}$. Compounds on the surface of particles that have ionization potentials below the energy of the incident photons will release an electron that is subsequently removed with an ion trap. The positively charged particle is collected on a filter that is connected to an electrical ground and the electrical potential between the ion trap and positively charged filter creates an electrical current, proportional to the number of ions that reach the filter per unit time and is measured with an electrometer. The ionization potentials of PPAH on the surfaces of particles are generally below the energy of the incident photons; however, the PAS is also sensitive to elemental carbon that has a work function of $4.4 \mathrm{eV}$. Some other organic compounds can also be ionized (Matter et al., 1999) and contribute to the signal from the PAS; hence, the signal from the PAS should be considered a relative, rather than absolute, indicator of the concentration of mixtures of PPAH, elemental carbon and some trace amounts of other organics. The manufacturer cautions that the PAS must be carefully calibrated with the aerosol mixture being studied if the results are to be interpreted quantitatively. This type of calibration is difficult, if not impossible, for an urban environment where the aerosol mixture will change significantly depending on the relative fractions of elemental carbon and organics. Given the uncertainties in absolute value, the results from the PAS will be reported as a mass concentration of $\mathrm{PPAH}^{*}$, where the asterisk indicates that this quantity is only a relative indicator of PPAH.

Carbon monoxide was not part of the instrument package used in the current study; however, it is a useful tracer for primary emissions and can also indicate changes in the height of the boundary layer (Baumgardner et al., 2003). The CO used in the following analysis is from measurements made with the Mexico City pollution monitoring network, Red Automatica de Monitoreo Ambiental (RAMA). Two RAMA stations are within five kilometers of the measurement site discussed below. The hourly $\mathrm{CO}$ values from these stations were averaged to obtain the data reported here.

\section{Results}

The measurement site is on the roof of the building of the Centro de Ciencias de la Atmósfera (CCA) inside the campus of the Universidad Nacional Autónoma de México (UNAM). The university is located in the southwest quadrant of the Mexico City basin and the CCA building $\left(19.6^{\circ} \mathrm{N}\right.$, $99.10^{\circ} \mathrm{W}$ ) is $2288 \mathrm{~m}$ above sea level. The university campus is in a residential area with no significant industrial or commercial activities; however, nearby there is a steady flow of auto and bus traffic related to the circulation of university staff and students. Approximately $400 \mathrm{~m}$ to the southeast is the subway terminal where more than 400 buses collect passengers daily (Peralta et al., 2006).

The particle instrumentation was connected to a common manifold that draws its air from a fifteen meter chimney 




Fig. 3. Typical diurnal evolution derived from averaging all sampling days, for (a) $\mathrm{CO}$, (b) $\mathrm{CN}$, and (c) $\mathrm{PPAH}^{*}$. The vertical bars indicate one standard deviation and represent an estimate of the dayto-day and year to year variability.

ventilated at a rate of approximately $901 \mathrm{~min}^{-1}$. All the instruments except the SP2 were operated $24 \mathrm{~h}$ a day. The data reported here are from 27 April to 1 May 2003 and 2-8 April 2005. The same SP2, CN counter, PSAP and nephelometer were used in both years. The SP2 was only operated from 07:00 to 18:00 LST in 2003 but made measurements $24 \mathrm{~h}$ a day in 2005. The PPAH* results are only from the 2005 campaign. Unless noted otherwise, the data discussed below represent a compilation from both years, with the exception of the $\mathrm{PPAH}^{*}$.

The $\mathrm{CN}$ concentration, $B_{\text {scat }}$, and $B_{\text {abs }}$ were output to the data system at $1 \mathrm{~Hz}$ and the PPAH* $^{*}$ measurements are six second averages. The SP2 records information on every particle; however, as a result of the very high data rates and large quantity of data, this instrument was set to record data during a one minute period out of every ten minutes. All of the parameters were averaged over ten minute intervals; however, the RAMA CO data were only available as hourly averages.

Examination of the time series for $\mathrm{CN}, \mathrm{CO}$ and $\mathrm{PPAH}^{*}$ (Figs. 3a-c) indicates a reproducible diurnal pattern with the daily maxima occurring at approximately the same time each day. These figures are averages over the entire sampling pe-
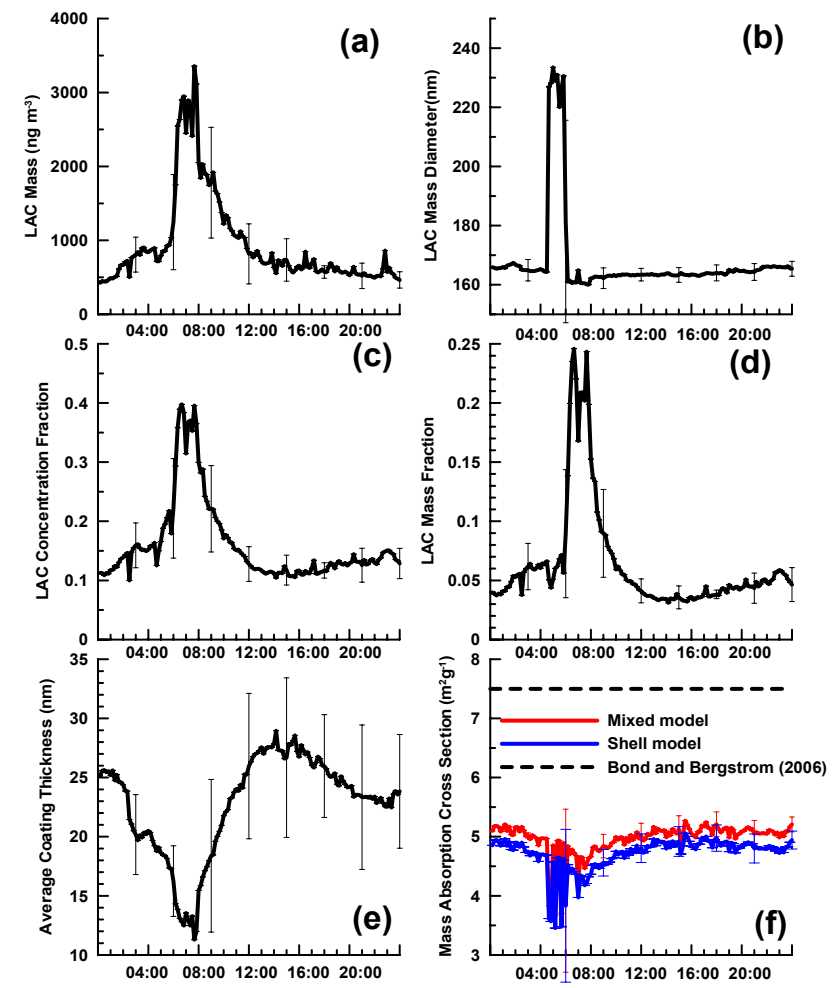

Fig. 4. As in Fig. 4 but for (a) LAC mass, (b) LAC $D_{\text {mass-eqv, }}$ (c) LAC concentration fraction, (d) LAC mass fraction, (e) Average thickness of coating on the LACC and f) mass absorption cross section assuming either a mixing (red) or shell (blue) optical model for coated LAC. The dashed line in (f) represents the value recommended by Bond and Bergstrom (2006).

riod, a total of 14 days from 2003 and 2005. The standard deviation about the averages, indicated by the vertical bars, is a measure of the day to day and year to year variability. Given that these measurements are from 2003 and 2005, the relatively low standard deviation suggests that these diurnal trends did not change significantly between the two years, either in the peak magnitudes or the time of the maxima. Note that the values of $\mathrm{CO}, \mathrm{CN}, \mathrm{PPAH}^{*}$ all increase rapidly at approximately 06:00 LST from very low and fairly constant nighttime values. Larger day-to-day variability, represented by the standard deviations, is evident in all parameters until sunset ( 19:00 LST) except for PPAH* which decreases significantly both in magnitude and variability after 10:00 LST.

Figures $4 \mathrm{a}-\mathrm{f}$ show the daily averages of the LAC mass concentration, $D_{\text {mass_eqv }}$, the ratios of the LAC number and mass concentrations to the total concentrations, the coating thickness of non-light absorbing material on the LAC and the derived mass absorption cross section, MAC. As in Fig. 3, the time series in each panel represent averages over the 14 days. All of the parameters shown in Figs. 3 and 4, except $D_{\text {mass_eqv, }}$ show trends that are dominated by two processes: 1) primary emissions from fossil fuel combustion and 

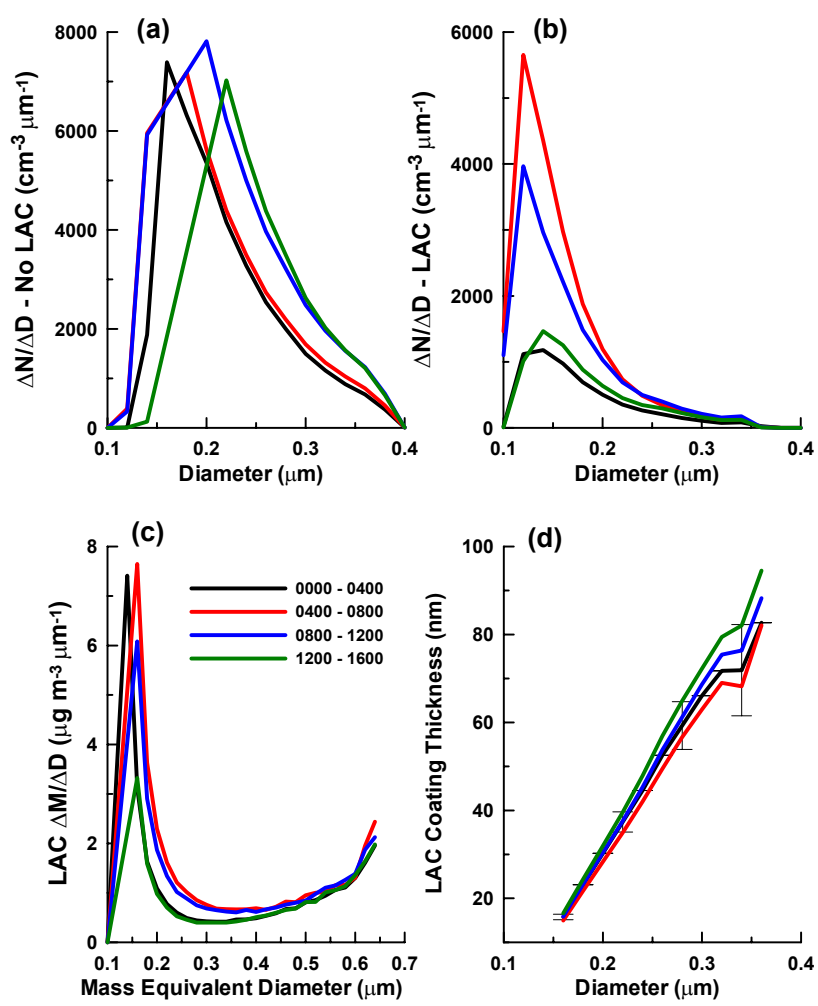

Fig. 5. These size distributions are daily averages every four hours, from midnight until 16:00 LST, for the 14 days of sampling, and show the number concentrations of particles with no LAC (a), with LAC (b), the LAC mass concentration (c) and the thickness of coating on the LAC particles (d).

2) mixing and dilution. Combustion of gasoline and diesel fuel is the primary source of $\mathrm{CO}$ and LAC, respectively, in Mexico City (Baumgardner et al., 2002). The onset of major vehicular movement is at 06:00 LST and continues unabated throughout the day until approximately 2000 (PROAIRE, 1997). Figures $3 a$ and $4 a$ show that CO and LAC mass reach their peak at 08:00 LST. Further increase in near-surface concentration is limited by the growth of the boundary layer after sunrise due to surface heating (Whiteman et al., 2000) that leads to turbulent mixing and dilution of gases and particles (Fast et al., 1998; Raga et al., 1999). The decrease observed in the CO and LAC mass after 09:00 LST is a result of this process.

Although the maximum period of traffic is from 06:00 to 18:00 there is continuing vehicular activity $24 \mathrm{~h}$ a day, as is seen by the non-rush hour levels of CO and LAC mass of $0.5 \mathrm{ppm}$ and $1000 \mathrm{ng} \mathrm{m}^{-3}$. The total particle concentration, represented by the $\mathrm{CN}$ measurements (Fig. 3b), follows a similar trend as $\mathrm{CO}$ and LAC mass. The $\mathrm{CN}$ rarely decreases below $10000 \mathrm{~cm}^{-3}$ and only during the nighttime when dayto-day variability is at a minimum. Of all the environmental variables measured only the $\mathrm{PPAH}^{*}$ decreases to values below its detection limit of $5 \mathrm{ng} \mathrm{m}^{-3}$. The PPAH $^{*}$ reaches a maximum at the same time as the $\mathrm{CN}$, indicating that the majority of the particles containing PAH are quite small, those that dominate the $\mathrm{CN}$ concentration.

The average mass equivalent diameter (Fig. 4b) varies only slightly throughout the day except for a one hour period from 05:00 to 06:00, when there is an abrupt increase from 165 to $230 \mathrm{~nm}$. The source of this shift is unknown at this time. As seen in Figs. $3 \mathrm{c}$ and d, the relative fraction of particles that contain LAC and the relative amount of LAC mass in the particles increases during the morning rush hour. The fraction of particles that have LAC increases by a factor of four from 10\% to $40 \%$ from 06:00 to 10:00 LST and the fraction of LAC mass increases by a factor of five from $5 \%$ to $25 \%$ of the total mass. The thickness of the coating of non-light absorbing material on the LAC reaches its minimum at the hour of maximum LAC mass then increases to its maximum thickness at 16:00 before decreasing in the late afternoon and early evening.

The mass absorption cross sections, derived using both the homogeneous mixture and shell models for the LAC, change only slightly during the day between $4.5 \pm 0.2$ and $5.0 \pm 0.2 \mathrm{~m}^{2} \mathrm{~g}^{-1}$. The minimum occurs when the LAC mass reaches its peak. These values of MAC are within the range reported in the literature but are somewhat less than the value of $7.5 \pm 1.2 \mathrm{~m}^{2} \mathrm{~g}^{-1}$ suggested by Bond and Bergstrom (2006) for fresh LAC. These are also less than the $8-10 \mathrm{~m}^{2} \mathrm{~g}^{-1}$ estimated by Barnard et al. (2005) from column measurements made with photometers.

The distributions as a function of diameter for the number concentration with and without LAC, LAC mass concentration and coating thickness are presented in Figs. 5a-d. The measurements were separated into six, four hour time periods and averaged over all days. The four curves in each panel are over the intervals 00:00-04:00, 04:00-08:00, 08:00-12:00 and 12:00-16:00. The time periods from 16:00-24:00 are not shown given that they are similar to the 12:00 to $16: 00$ spectra. We observe that the size distributions of particles with and without LAC have different diurnal trends. The non-LAC size distributions (Fig. 5a) increase in concentrations over all sizes between the first and third time period and the tail of the distribution continues to increase throughout the day, indicating that particles are growing, most likely through condensation. The mode of the distributions is at $160 \mathrm{~nm}$.

The number concentration size distributions of particles containing LAC (Fig. 5b) are narrow from 08:00 to 12:00 with peaks at $130 \mathrm{~nm}$ and then broaden during the afternoon and early morning while still maintaining their maxima at $130 \mathrm{~nm}$. This difference in the diameter of maximum concentration between the non-LAC and LAC distributions might be a result of the presence of LAC material that could be inhibiting condensational growth. The alternative explanation is that the sizes, derived as optical diameters, are smaller as a result of the internal heating as the LAC absorbs light, an effect that was described earlier in this paper. 
The size distributions of the LAC mass, plotted as a function of mass equivalent rather than optical diameter (Fig. 5c), suggest that the maximum in mass might be found at a diameter smaller than the lower threshold of the SP2. The increasing mass concentration with sizes larger than $400 \mathrm{~nm}$ indicate that there is LAC mass at diameters larger than the $650 \mathrm{~nm}$ upper threshold. The LAC coating thickness (Fig. 5d) is a linear function of the optical diameter with very little sensitivity to the time of day. Given that internal heating may lead to an underestimate of $D_{\text {optical }}$ from which the thickness is derived, the layer of the coating may also be underestimated.

\section{Discussion}

A detailed examination of the diurnal trends provides further insight with respect to the underlying processes that control the evolution of aerosol properties in Mexico City. The increase in the thickness of the coating on LAC (Fig. 5c), after its minimum at 08:00, is an indicator of the ageing of LAC as non-light absorbing material condenses on the surface. Similar thickening of the coating on ageing LAC has been measured with an SP2 downwind of Tokyo (M. Shiraiwa, personal communication).

The rapid decrease of PPAH (Fig. 3c), within four hours of its maximum, suggests a removal process related to photochemical reactions. This behavior has been previously reported by Marr et al. (2006) who concluded that the rapid decay in PPAH is a result of secondary organic material that condenses on the PAH-containing particles. This suppresses the response of the PAS 2000; hence, not only is the evolution of PPAH not linked to the dilution, as is the case with related primary emission variables, but it also urges caution in using this type of analyzer for analyzing urban PPAH.

Figures $6 \mathrm{a}-\mathrm{c}$ compare the absorption and scattering coefficients and the single scattering albedo determined directly from the nephelometer and PSAP (black curves) with those obtained indirectly from the SP2 measurements (red and blue curves). The $B_{\text {abs }}$ from the PSAP and SP2 are well correlated but the PSAP values are on average 2.3 times larger than the SP2. This difference is primarily a result of the lower and upper sizing limits of the SP2, as discussed previously. According to estimates by Schwarz et al. (2006), the SP-2 loses approximately $40 \%$ of the LAC mass that is smaller than the lower size threshold. These estimates were based on lognormal fits to the mass size distribution and did not account for LAC that was larger than the upper size threshold. In addition, the Schwarz et al. (2006) estimates were for LAC in the free troposphere whereas the LAC in the present study is within the highly polluted boundary layer and close to the source of emissions. Hence it is likely that in this environment, more than $50 \%$ of the LAC is in particles smaller than $120 \mathrm{~nm}$. Evidence that there are LAC larger than $650 \mathrm{~nm}$ is seen by Johnson et al. (2005) who saw clusters of carbon particles larger than $1000 \mathrm{~nm}$ when evaluating Mexico
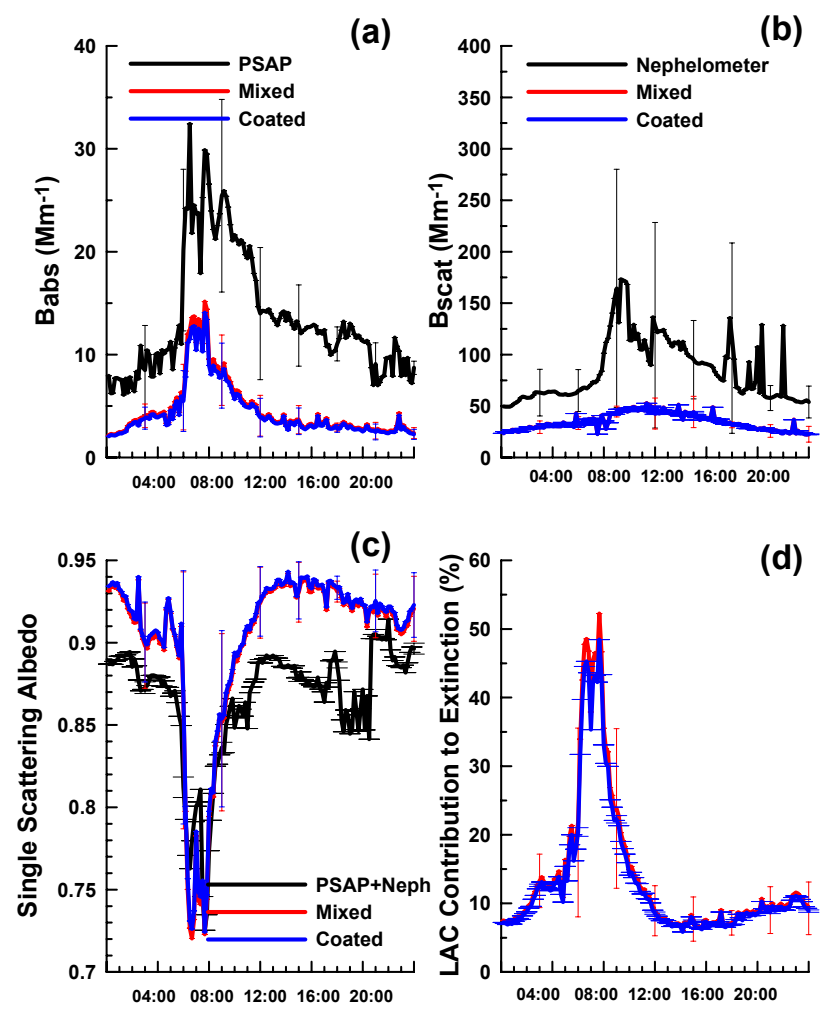

Fig. 6. The evolution of the particle optical properties, derived from averaging all sampling days, is compared here for $B_{\text {abs }}$ (a), $B_{\text {scat }}$ (b), and single scattering albedo (c), derived indirectly from the SP2 measurements (red and blue for the mixed and shell optical models) and directly from the nephelometer and PSAP (black). The contribution of the LAC to the total extinction is shown in panel (d).

City samples with electron microscopy. These clusters might have a mass equivalent diameter smaller than $1000 \mathrm{~nm}$ but their presence in a fairly small number of samples indicate that they might provide a measurable contribution to the total mass of LAC and the light absorption. The difference between the $B_{\text {abs }}$ derived from the SP2 using the homogeneous mixture (red curve in Fig. 6a) and the shell (blue curve) models was insignificant. This was also observed in the derivation of $\sigma_{\text {abs }}$ using the two models (Fig. 4f).

The $B_{\text {scat }}$ measured by the nephelometer is approximately twice the value derived from the SP2 is due to the truncation of the SP2 measurements above $400 \mathrm{~nm}$ for the optical diameter. The single scattering albedo (SSA) derived from the PSAP and nephelometer is in much better agreement with that derived from the SP2 because the SSA derived from the SP2 is on a particle by particle basis and is only slightly affected by the truncation error.

The fraction of the total light extinction that is contributed by LAC-containing particles is shown in Fig. $6 \mathrm{~d}$ indicating that these particles contribute as much as $50 \%$ of the total extinction in the morning during peak rush hour and approximately $10 \%$ during the remainder of the day. Figure 7 shows 


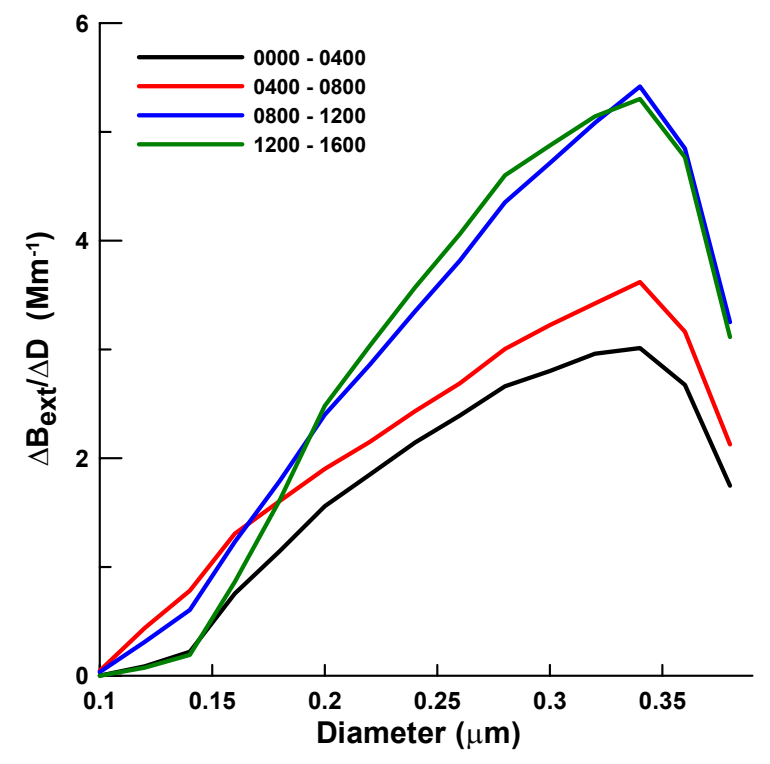

Fig. 7. These size distributions of the extinction coefficient derived from the SP2 measurements are daily averages every four hours for the 14 days of sampling.

the size distributions of the extinction coefficient divided into four time periods. Here we see that the majority of the extinction is from particles larger than $300 \mathrm{~nm}$; however, it is clear that a large fraction of the extinction could be in particles larger than $400 \mathrm{~nm}$. This figure also illustrates how particle growth during the day increases the extinction coefficient.

The $\mathrm{CO}$ concentrations are useful for inferring LAC when LAC measurements are not available (Baumgardner et al., 2002). As shown in Fig. 8 the LAC in Mexico City, measured by the SP2, is related to the CO by a factor of 1012 , one ppm of $\mathrm{CO}$ is associated with $1012 \mathrm{ng} \mathrm{m}^{-3}$ of BC. If we assume that the LAC outside of the SP2 measurement range can be estimated from the ratio of $B_{\text {abs }}$ measured by the PSAP and SP2, then the LAC to CO relationship is 2226. After adjusting to standard atmospheric pressure and temperature, and converting ppm to $\mathrm{mg} \mathrm{m}^{-3}$, the LAC to CO relationship is approximately one microgram of LAC for every milligram of $\mathrm{CO}$. This equal to the relationship that was previously derived by Baumgardner et al. (2002) based upon the $B_{\text {abs }}$ measured with the same PSAP but with LAC derived from evolved gas analysis of particles on filters. According to the 1999 inventory of emissions (PROAIRE, 1999), Mexico City produces approximately $1.2 \times 10^{6}$ metric tons of $\mathrm{CO}$ yearly. Using the LAC to CO relationship we predict 1200 metric tons of LAC emitted yearly in Mexico City. This is similar to the value of $1700 \pm 200$ metric tons predicted by Jiang et al. (2006) who used measurements of $B_{\text {abs }}$ measured with an aethalometer to estimate black carbon mass.

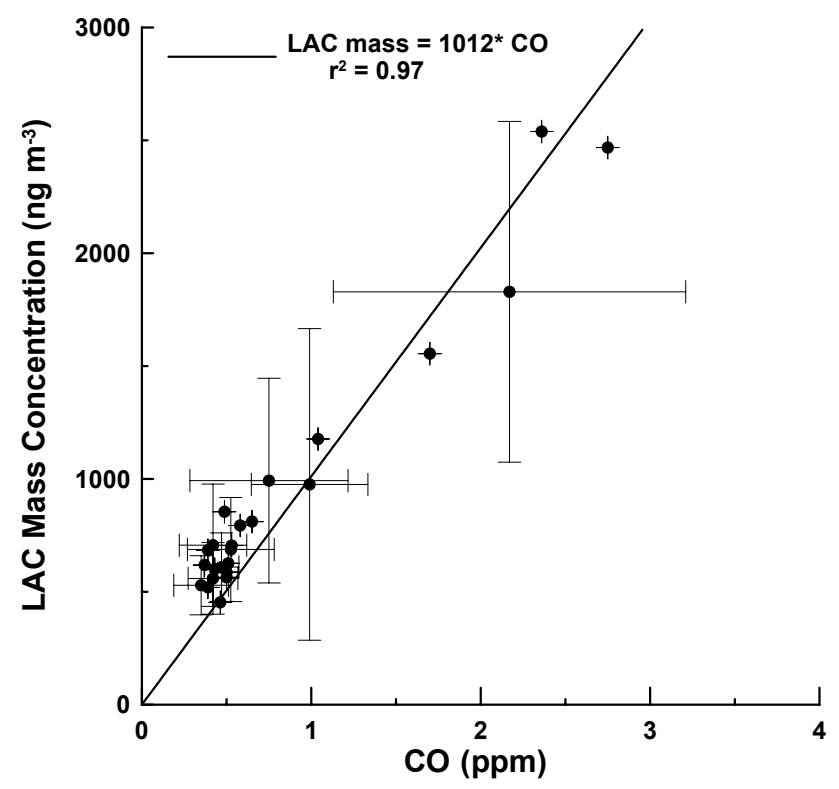

Fig. 8. Relationship between $\mathrm{BC}$ mass and $\mathrm{CO}$ derived from present study, and similar to that obtained in (Baumgardner et al., 2002).

\section{Summary}

Measurements of the LAC in individual, internally mixed aerosol particles were made with the SP2 in April of 2003 and 2005. The measurement technique uses light scattering and incandescence to derive the optical and LAC mass equivalent diameters from which the coating of non-light absorbing material can be estimated. Particle optical properties were also derived from the SP2 measurements and compared with those directly measured with a nephelometer and soot photometer. The characteristics of the LAC were compared with the $\mathrm{CO}, \mathrm{CN}$, and PPAH concentrations, environmental variables that are also linked to primary emissions.

The LAC, $\mathrm{CO}$ and $\mathrm{CN}$ have matching diurnal trends that are associated with traffic patterns and boundary layer growth. The LAC mass reaches a daily average maximum of $3000 \pm 1000 \mathrm{ng} \mathrm{m}^{-3}$ but has a nighttime, background level of $1000 \mathrm{ng} \mathrm{m}^{-3}$. The number of particles containing LAC ranges between $10 \%$ to $40 \%$ of all particles between $100 \mathrm{~nm}$ and $400 \mathrm{~nm}$ and the LAC contributes between $5 \%$ and $25 \%$ of the total mass in this size range. The LAC particles have the thinnest coating of non-light absorbing material, about $12 \mathrm{~nm}$, in the morning at 08:00 but increases to a maximum thickness of $30 \mathrm{~nm}$ by mid-afternoon as the LAC particles age.

The absorption coefficient derived from the SP2 is less than $50 \%$ of the direct measurements made with the PSAP, indicating that more than $50 \%$ of the LAC is in particles smaller than $100 \mathrm{~nm}$ or larger than $400 \mathrm{~nm}$. LAC contributes to $50 \%$ of the total light extinction during the 07:0008:00 rush hour then decreases to approximately $10 \%$ the 
remainder of the day. LAC mass is emitted at a rate of 1200 metric tons per year in Mexico City, based upon the SP2 measurements and correlations between LAC and $\mathrm{CO}$ and taking into account the LAC outside of the size range of the SP2.

Acknowledgements. The SP2 was developed under Navy contract \#N00014-01-C-0335. We would like to thank A. Retama of the Mexico City environmental service for providing the $\mathrm{CO}$ data from the RAMA network.

Edited by: L. T. Molina

\section{References}

Baumgardner, D., Raga, G. B., Kok, G., Ogren, J., Rosas, I., Baez, A., and Novakov, T.: On the evolution of aerosol properties at a mountain site above Mexico city, J. Geophys. Res., 105, 22 243$22253,2000$.

Baumgardner, D., Raga, G., Peralta, O., Rosas, I., Castro, T., Kuhlbusch, T., John, A., and Petzold, A.: Diagnosing black carbon trends in large urban areas using carbon monoxide measurements, J. Geophys. Res., 107(D21), 8342, doi:10.1029/2001JD000626, 2002.

Baumgardner, D., Kok, G., and Raga, G.: Warming of the Arctic lower stratosphere by light absorbing particles, Geophys. Res. Lett., 31, L06117, doi:10.1029/2003GL018883, 2004.

Barnard, J. C., Kassianov, E. I., Ackerman, T. P., Frey, S., Johnson, K., Zuberi, B., Molina, L. T., Molina, M. J., Gaffney, J. S., and Marley, N. A.: Measurements of black carbon specific absorption in the Mexico City metropolitan area during the MCMA 2003 field campaign, Atmos. Chem. Phys., 7, 1645-1655, 2007

Bohren, C. F. and Huffman, D. R.: Absorption and Scattering of Light by Small Particles, John Wiley, Hoboken, N.J., 1983.

Bond, T. C., Anderson, T. L., and Cambell, D.: Calibration and intercomparison of filter-based measurements of visible light absorption by aerosols, Aerosol Sci. Technol., 30, 582-600, 1999.

Bond, T. C. and Bergstrom, R. W.: Light absorption by carbonaceous particles: An investigative review, Aerosol Sci. Technol., 40, 27-67, 2006.

Bond, T. C., Habib, G., and Bergstrom, R. W.: Limitations in the enhancement of visible light absorption due to mixing state, J. Geophys. Res., 111(D20), D20211, doi:10.1029/2006JD007315, 2006.

Charlson, R. J., Scwartz, S. E., Hales, J. M., Cess, R. D., Coakely, J. A., Hanson, J. E., and Hoffmann, D. J.: Climate forcing by anthropogenic aerosols, Science, 255, 423-430, 1992.

Clarke, A. D., Shinozuka, Y., Kapustin, V. N., et al.: Size distributions and mixtures of dust and black carbon aerosol in Asian outflow: Physiochemistry and optical properties, J. Geophys. Res., 109, D15S09, doi:10.1029/2003JD004378, 2004.

Comisión Ambiental Metropolitana: Inventario de Emisiones de la Zona Metropolitana del Valle de México, Secretaría del Medio Ambiente, Gobierno de México, México, 2004.

Dickerson, R., Kondragunta, S., Stenchikov, G., Civerolo, K., and Doddridge, B.: The impact of aerosols on solar UV radiation and photochemical smog. Science, 278, 827-830, 1997.

Fast, J. and Zhong, S.: Meteorological factors associated with inhomogeneous ozone concentrations within the Mexico City basin, J. Geophys. Res., 103, 18 927-18 946, 1998.
Fuller, K. A., Malm, W. C., and Kreidenweis, S. M.: Effects of mixing on extinction by carbonaceous particles, J. Geophy. Res., 104, 15 941-15 954, 1999.

Gao, R. S., Schwarz, J. P., Kelly, K. K., Fahey, D. W., Watts, L. A., Thompson, T. L., Spackman, J. R., Slowik, J. G., Cross, E. S., Han, J.-H., Davidovits, P., Onasch, T. B., and Worsnop, D. R.: A novel method for estimating light-scattering properties of soot aerosols using a modified single-particle soot photometer, Aerosol Sci. Technol., 41, 125-135, 2007.

Ghan, S. J. and Penner, J. E.: Smoke, effects on climate, in: Encyclopedia of Earth System Science, Vol. 4, edited by: Nierenberg, W. A., Academic Press, San Diego, CA., 191-198, 1992.

Hobbs, P. V.: Aerosol-Cloud-Climate Interactions, Academic Press, Inc., New York, 480 pp., 1991.

Jacobson, M.: Studying the effects of aerosols on vertical photolysis rate coefficient and temperature profiles over an urban airshed, J. Geophys. Res., 103, 10 593-10 604, 1998.

Jiang, M., Marr, L. C., Dunlea, E. J., Herndon, S. C., Jayne, J. T., Kolb, C. E., Knighton, W. B., Rogers, T. M., Zavala, M., Molina, L. T., and Molina, M.: Vehicle fleet emissions of black carbon, polycyclic aromatic hydrocarbons, and other pollutants measured by a mobile laboratory in Mexico City, Atmos. Chem. Phys., 5, 3377-3387, 2005,

http://www.atmos-chem-phys.net/5/3377/2005/.

Johnson, K. S., Zuberi, B., Molina, L. T., Molina, M. J., Iedema, M. J., Cowin, J. P., Gaspar, J. D., Wang, C., and Laskin, A.: Processing of soot in an urban environment: case study from the Mexico City Metropolitan Area, Atmos. Chem. Phys., 5, 30333043, 2005, http://www.atmos-chem-phys.net/5/3033/2005/.

Kondo, Y., Komazaki, Y., Miyazaki, Y., Moteki, N., Takegawa, N., Kodama, D., Deguchi, S., Nogami, M., Fukuda, M., Miyakawa, T., Morino, Y., Koike, M., Sakurai, H., and Ehara, K.: Temporal Variations of Elemental Carbon in Tokyo, J. Geophys. Res., 111, D12205, doi:10.1029/2005JD006257, 2006.

Liousse, C., Cachier, H., and Jennings, S. G.: Optical and thermal measurements of black carbon aerosol content in different environments: variation of the specific attenuation cross section, Atmos. Environ. Part A, 27, 1203-1211, 1993.

Marr, L. C., Dzepina, K., Jimenez, J. L., Reisen, F., Bethel, H. L., Arey, J., Gaffney, J. S., Marley, N. A., Molina, L. T., and Molina, M. J.: Sources and transformations of particle-bound polycyclic aromatic hydrocarbons in Mexico City, Atmos. Chem. Phys., 6, 1733-1745, 2006, http://www.atmos-chem-phys.net/6/1733/2006/.

Matter, U., Siegmann, H. C., and Burtscher, H.: Dynamic field measurements of submicron particles from diesel engines, Environ. Sci. Technol., 33, 1946-1952, 1999.

Mikhailov, E. F., Vlasenko, S. S., Podgorny, I. A., Ramanathan, V., and Corrigan, C. E.: Optical Properties of Soot-Water Drop Agglomerates: An Experimental Study, J. Geophys. Res., 111, D07209, doi:10.1029/2005JD006389, 2006.

Moteki, N. and Kondo, Y.: Effects of mixing state on black carbon measurement by Laser-Induced Incandescence, Aerosol Sci. Technol., 41, 398-417, 2007.

Novakov, T.: BC in the atmosphere, in: Particulate carbon: Atmospheric Life Cycle, edited by: Wolff, G. T. and Klimisch, R. L., Plenum Press, New York, 19-37, 1982.

Peralta, O., Baumgardner, D., and Raga, G. B.: Spectrothermogra- 
phy of Carbonaceous particles, J. Atmos. Chem., published online, doi:10.1007/s10874-007-9070-1, 2007.

Petzold, A., Kopp, C., and Niessner, R.: The dependence of the specific attenuation cross-section on black carbon mass fraction and particle size, Atmos. Environ., 31, 661-672, 1997.

Pöschl, U.: Aerosol particle analysis: Challenges and progress, Anal. Bioanal. Chem., 375, 30-32, 2002.

PROAIRE:. Programa para mejorar la calidad del aire en el valle de México: 1995-2000, Departamento del Distrito Federal; Gobierno del Estado México; Secretaría de Medio Ambiente, Recursos Naturales y Pesca y Secretaria de Salud, 1st ed., pp. 244, Mexico, 1999.

Raga, G. B., Kok, G. L., Baumgardner, D., and Rosas, I.: Some aspects of boundary layer evolution in Mexico City, Atmos. Environ., 33, 5013-5021, 1999.

Raga, G. B. and Raga, A.: On the formation of elevated ozone peak in Mexico City, Atmos. Environ., 34, 4097-4102, 2000.

Raga, G. B., Baumgardner, D., Peralta, O., and Saavedra, M. I.: Carbon content of size fractionated particles in Mexico City, European Aerosol Conference, 1-5 September 2003, Madrid, S477-S478, 2003.

Schuster, G. L., Dubovik, O., Holben, B. N., and Clothiaux, E. E.: Inferring black carbon content and specific absorption from AERONET retrievals, J. Geophys. Res.-Atmos., 101, 10-17, doi:10.1029/2004JD004548, 2005.
Schwarz, J. P., Gao, R. S., Fahey, D. W., Thomson, D. S., Watts, L. A., Wilson, J. C., Reeves, J. M., Baumgardner, D. G., Kok, G. L., Chung, S., Schulz, M., Hendricks, J., Lauer, A., Kärcher, B., Slowik, J. G., Rosenlof, K. H., Thompson, T. L., Langford, A. O., Lowenstein, M., and Aikin, K. C.: Single-particle measurements of mid latitude black carbon and light-scattering aerosols from the boundary layer to the lower stratosphere, J. Geophys. Res., 111, D16207, doi:10.1029/2006JD007076, 2006.

Seinfeld, J. H. and Pandis, S. N.: Atmospheric chemistry and physics, John Wiley and Sons, N.Y., 1326 pp, 1998.

Slowik, J. G., Cross, E., Han, J., Davidovits, P., Onasch, T. B., Jayne, J. T., Williams, L. R., Canagaratna, M. R., Worsnop, D. R., Chakrabarty, R. K., Arnott, W. P., Schwarz, J. P., Gao, R. S., Fahey, D. W., and Kok, G. L.: Intercomparison of instruments measuring black carbon content and optical properties of soot particles, Aerosol. Sci. Technol., 41, 295-314, 2007.

Stephens, M., Turner, N., and Sandberg, J.: Particle identification by Laser Induced Incandescence in a solid state laser cavity, Appl. Opt., 42, 3726-3736, 2003.

Twitty, J. T. and Weinman, J. A.: Radiative properties of carbonaceous aerosols, J. Appl. Met., 10, 725-731, 1971.

Volz, F. E.: Infrared refractive index of atmospheric aerosol substances, Appl. Opt., 11, 755-759, 1972.

Whiteman, C. D., Zhong, S., Bian, X., Fast, J. D., and Doran, J. C.: Boundary layer evolution and regional-scale diurnal circulations over the Mexico Basin and Mexican Plateau, J. Geophys. Res., 105, 10081-10 102, 2000. 